This item was submitted to Loughborough's Research Repository by the author.

Items in Figshare are protected by copyright, with all rights reserved, unless otherwise indicated.

\title{
Cultural differences in the relationships among autonomy support, psychological need satisfaction, subjective vitality, and effort in British and Chinese physical education
}

\section{PLEASE CITE THE PUBLISHED VERSION}

http://journals.humankinetics.com/jsep-back-issues/jsep-volume-32-issue-5-october/cultural-differences-inthe-relationships-among-autonomy-support-psychological-need-satisfaction-subjective-vitality-and-effort-inbritish-and-chinese-physical-education

\section{PUBLISHER}

(c) Human Kinetics, Inc.

\section{VERSION}

AM (Accepted Manuscript)

\section{LICENCE}

CC BY-NC-ND 4.0

\section{REPOSITORY RECORD}

Taylor, lan M., and Chris C. Lonsdale. 2019. "Cultural Differences in the Relationships Among Autonomy Support, Psychological Need Satisfaction, Subjective Vitality, and Effort in British and Chinese Physical Education". figshare. https://hdl.handle.net/2134/15370. 
This item was submitted to Loughborough's Institutional Repository (https://dspace.lboro.ac.uk/) by the author and is made available under the following Creative Commons Licence conditions.

\section{creative
commons}

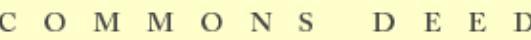

Attribution-NonCommercial-NoDerivs 2.5

You are free:

- to copy, distribute, display, and perform the work

Under the following conditions:

Attribution. You must attribute the work in the manner specified b the author or licensor.

Noncommercial. You may not use this work for commercial purposes.

No Derivative Works. You may not alter, transform, or build upon this work.

- For any reuse or distribution, you must make clear to others the license terms of this work.

- Any of these conditions can be waived if you get permission from the copyright holder.

Your fair use and other rights are in no way affected by the above.

This is a human-readable summary of the Leqal Code (the full license).

\section{Disclaimer 만}

For the full text of this licence, please go to: http://creativecommons.org/licenses/by-nc-nd/2.5/ 
PSYCHOLOGICAL NEEDS ACROSS CULTURES

Running Head: PSYCHOLOGICAL NEEDS ACROSS CULTURES

Cultural differences in the relationships among autonomy support, psychological need satisfaction, subjective vitality, and effort in British and Chinese physical education

Manuscript Submitted: January $8^{\text {th }}, 2010$

Manuscript Resubmitted: April 7th, 2010

Manuscript Resubmitted: May 27 $7^{\text {th }}, 2010$ 


\begin{abstract}
Using basic psychological needs theory (BPNT; Ryan \& Deci, 2000) as our guiding framework, we explored cultural differences in the relationships among Physical Education (PE) students’ perceptions of teacher autonomy support, psychological need satisfaction, subjective vitality and effort in class. Seven hundred and fifteen students (age range from 1315 years) from the UK and Hong Kong, China completed a multi-section inventory during a timetabled PE class. Multilevel analyses revealed that the relationships among autonomy support, subjective vitality and effort were mediated by students’ perceptions of psychological need satisfaction. The relationship between autonomy support and perceptions of competence was stronger in the Chinese sample, compared to the UK sample. Also, the relationship between perceptions of relatedness and effort was not significant in the Chinese students. The findings generally support the pan-cultural utility of BPNT and imply that a teacher-created autonomy supportive environment may promote positive student experiences in both cultures.
\end{abstract}

Key Words: Autonomy, Competence, Relatedness, Self-determination 
Cultural differences in the relationships among autonomy support, psychological need satisfaction, subjective vitality, and effort in British and Chinese physical education Why do some students participate in Physical Education (PE) with energy and sustained effort yet other students are lacklustre and put forth minimal effort? Sustained empirical investigation has shown that the satisfaction versus frustration of innate psychological needs can potentially explain human behavior and well-being (Baumeister \& Leary, 1995; Sheldon, Elliot, Kim \& Kasser, 2001). In a comparison of ten potential psychological needs, Sheldon and colleagues found that those needs described in selfdetermination theory (SDT; Ryan \& Deci, 2000) are particular useful in explaining satisfying events. In view of this empirical support, SDT has been applied to educational contexts with the aim of discovering how to facilitate positive student experiences. Some scholars, however, have questioned the pan-cultural benefits of satisfying the psychological needs advocated within SDT (Iyengar \& Lepper, 1999; Markus \& Kitayama, 2003). In the present study we explored possible cultural differences in the relationships among determinants and consequences of Hong Kong Chinese and UK PE students’ psychological need satisfaction. We also aimed to decompose these relationships into student- and class-level effects.

Advocates of SDT have proposed that individuals have an inherent striving to satisfy psychological needs for autonomy, competence, and relatedness. Autonomy refers to the need for self-governance and self-endorsement of behaviors (Ryan \& Deci, 2000). Competence reflects the requirement to be efficacious and to achieve desired outcomes (White, 1959). Relatedness refers to the need to feel connected to significant others (Baumeister \& Leary, 1995). According to basic psychological needs theory (BPNT), a sub-theory within SDT, when these psychological needs are fulfilled, effective functioning and well-being occur. For example, Gagné, Ryan, and Bargmann (2003) found that fluctuations in youth female gymnasts' daily need satisfaction positively predicted fluctuations in indices of psychological 
well-being (i.e., subjective vitality, positive affect, and self-esteem) over a four-week period. Similarly, satisfying individuals’ psychological needs has been positively linked to performance and quality of adjustment in the workplace (Baard, Deci, \& Ryan, 2004), psychological well-being in exercise contexts (Wilson, Longley, Muon, Rodgers, \& Murray, 2006), and lower burnout in athletes (Lonsdale, Hodge, \& Rose, 2009).

The adaptive consequences of satisfying individuals’ psychological needs have also been demonstrated in several countries adopting different cultural values. For instance, US and South Korean university students indicated that perceptions of autonomy, competence, and relatedness were important in their retrospective recall of life-satisfying experiences (Sheldon et al., 2001). In a similarly designed study within school settings, South Korean high school students reported that the three SDT-based psychological needs were salient during satisfying learning experiences (Jang, Reeve, Ryan, \& Kim, 2009). In a second study, these authors also found that the three psychological needs were prospectively linked to positive student outcomes, even after controlling for students' collectivist orientation (i.e., the extent to which individuals associate with the larger collective society; Hofstede, 2001).

Supplementing this research on the three SDT-based psychological needs, some scholars have focused on the relationship between the degree of autonomous motivation towards an activity and various important outcomes. For example, Chirkov, Ryan, Kim and Kaplan (2003) found that, despite differences in cultural orientations in American, Russian, Turkish, and South Korean university students, autonomous motivation was positively related to psychological well-being in all four sub-samples. Several researchers that have sampled one culture also found positive relationships between autonomous motivation and adaptive outcomes in Japanese (Nagasaku \& Arai, 2005); Israeli (Roth, Kanat-Maymon, Assor, \& Kaplan, 2006), Chinese (Lonsdale, Sabiston, Raedeke, Ha, \& Sum, 2009; Vansteenkiste, Zhou, Lens, \& Soenens, 2005), Canadian (Ratelle, Guay, Vallerand, Larose, \& Senécal, 
2007), and UK (Taylor, Ntoumanis, Standage, \& Spray, 2010) students (see also Chirkov, 2009 for a review on this topic).

Despite this persuasive support for the universal importance of the three psychological needs, other researchers have proposed that the relative importance of the three psychological needs may vary according to culture. In particular, some researchers consider autonomy as a creation of Western civilisation and less important in Eastern, collectivist cultures because a group’s needs are seen as paramount, rather than the needs of the individual (e.g., Iyengar \& Lepper, 1999; Markus \& Kitayama, 2003). Given this communal outlook, the need for a sense of relatedness to the collective may be of principal concern in Eastern cultures (Heine, Lehman, Markus, \& Kitayama, 1999). These contrasting arguments relating to the importance of autonomy need satisfaction may be a result of differing definitions. Markus and Kitayama viewed autonomy as analogous to interpersonal independence and individualism and, thus, maladaptive in cultures where self-affirmation occurs through positive relationships with others and meeting social norms (i.e., a conjoint model of agency). In these cultures, individuals are prone to follow external influences at the expense of their own preferences (Kim \& Markus, 1999; Kitayama, Snibbe, Markus, \& Suzuki, 2004). The satisfaction of autonomy is, therefore, only beneficial in societies that hold a disjoint model of agency in which the self is affirmed through independence and the expression of uniqueness (Markus \& Kitayama). In contrast, autonomy is defined within SDT as the intrapersonal propensity to be self-governed and to experience feelings of volition and endorsement of one’s behavior (Chirkov \& Ryan, 2001). According to self-determination theorists, therefore, even in cultures holding a conjoint model of agency, autonomy is essential to healthy functioning and orthogonal to independence and conformity. Thus, an individual can be autonomously dependent on another person or, equally, autonomously refuse to rely on the significant other (i.e., independent). 
Given that satisfying one’s psychological needs can lead to effective functioning and well-being, researchers have explored the social environments that lead to such processes. Research embedded in SDT has considered the degree to which the teacher provides an autonomy supportive environment for students (e.g., providing students with choice, offering a meaningful rationale for activities, and acknowledging students' feelings towards activities). Positive benefits of a teacher-created autonomy supportive environment have been found in Eastern countries such as South Korea (Jang et al., 2009), Singapore (Hagger, Chatzisarantis, Barkoukis, Wang, \& Baronowski, 2005), and Taiwan (Hardre et al., 2006), as well as Western countries such as the UK (Hagger et al., 2005) and USA (Reeve, Jang, Carrell, Jeon, Barch, 2004). Despite this empirical backing, however, alternative research has suggested that the support of students' autonomy by teachers may be of less importance in collectivist cultures because of predominant Confucian values that promote conformity, respect of superiors, obedience, and interdependence (Chao \& Tseng, 2002).

In the present study we adopted an SDT perspective and hypothesized that an autonomy supportive environment that satisfies students’ needs for autonomy, competence, and relatedness would lead to positive outcomes. Nonetheless, it is possible that subtle cultural differences do occur regarding the relative importance of autonomy support and each psychological need. In the present study we wished to explore this novel research question by exploring cultural differences in the strengths of the relationships among these constructs. For example, rather than asking “does autonomy support predict psychological need satisfaction and important consequences in collectivist and individualist cultures?”, we asked "is there a difference in the strength of the relationships among autonomy support, psychological need satisfaction, and important outcomes across collectivist and individualist cultures?”.

We aimed to examine the importance of the three psychological needs in the PE context. This is an important contribution to the research literature because PE-based research 
largely ignores the direct effects of psychological need satisfaction on important student outcomes; choosing instead to adopt an organismic integrative perspective (Deci \& Ryan, 2000), whereby the relationships among the psychological needs and positive psychological outcomes is indirect via individuals' self-determination towards the activity. As an exception, Taylor and colleagues (2010) found that inter-individual variation in all three psychological needs was positively associated with effort in UK PE students. In the present study we aimed to replicate this finding and extend it by simultaneously examining the impact of autonomy supportive teaching practices and psychological need satisfaction on effort in Hong Kong Chinese and UK PE students. We also examined the impact of these factors on students' subjective vitality, which refers to “a positive feeling of aliveness and energy” (Ryan \& Frederick, 1997; p. 529), as a proxy indicator of students’ organismic well-being.

Although no data were collected on cultural orientations in the present study, persuasive evidence exists that inhabitants of the UK and Hong Kong hold contrasting cultural values. For example, in his seminal text on world cultures, Hofstede (2001) presented large amounts of data that suggested Hong Kong and British cultures markedly differ in the degree of interpersonal influence a superior has over a subordinate (i.e., power distance) and the extent to which individuals associate with the collective (i.e., individualism/collectivism). These differences have been replicated in Chinese-based research, resulting in the suggestion that Hofstede’s work can be used as a suitable method for choosing cultures for comparison on an a priori basis (Chinese Culture Connection, 1987).

In the present study we also aimed to extend current knowledge by decomposing the relationships among the study variables into student- and class-level effects; something which no previous research has undertaken. Student-level effects (or within-class effects) refer to the extent to which a student's perceptions of autonomy support and psychological needs relative to his/her class mates' perceptions predict his/her subjective vitality and effort. This 
level of analysis provides an opportunity to examine whether students' contextual frame of reference impacts upon the relationships among the study variables. For example, two students who report the same levels of perceived competence may report different levels of effort because one student is surrounded by highly competent students in his/her class, whereas, the other participates in PE alongside incompetent peers. These social comparison effects have a long tradition in social (e.g., Suls \& Wheeler, 2000) and educational psychology (e.g., Trautwein, Lüdtke, Nagy, \& Marsh, 2009), yet they have not been considered within the SDT framework. In contrast, class-level effects reflect the extent to which class average perceptions of autonomy support and psychological need satisfaction are associated with students' subjective vitality and effort. This decomposing of effects is particularly important as relationships observed at one level of analysis may be different at the other. For example, Trautwein et al. (2009) proposed that individuals’ academic achievement is positively related to academic self-concept, yet, the reverse is true for schoollevel achievement because students have lower self-concept when they are surrounded by high achievers.

To summarize the present study, we explored the student- and class-level relationships among PE students’ perceptions of an autonomy supportive environment, psychological need satisfaction, subjective vitality, and effort in UK and Hong Kong Chinese high school students. Scant educational research has considered the direct effects of supporting students’ psychological needs on positive outcomes. Aligned with the theoretical tenets of SDT, we hypothesized that autonomy support would positively predict subjective vitality and effort in both cultures, at both the student- and class-levels of analysis. Further, we hypothesized that these relationships would be mediated by students’ perceptions of autonomy, competence, and relatedness. Aspects of these hypotheses are in contrast to some cross-cultural relativists (e.g., Chao \& Tseng, 2002; Iyengar \& Lepper, 1999; Markus \& 
Kitayama, 2003), who have proposed that autonomy and autonomy support are unrelated to optimal functioning in Eastern collectivist cultures, such as Hong Kong. In addition, selfdetermination theorists do not explicitly hypothesize any cultural differences in the magnitude of the relationships among the study variables; therefore, we did not expect to find any such differences.

Method

\section{Procedures and Participants}

The Chinese data were collected in Hong Kong, a special administrative region of China inhabited by approximately seven million people, 95\% of which are of Han Chinese ethnicity (Census and Statistics Department, 2010). The UK data were collected in Birmingham, the UK's second largest city inhabited by approximately one million people, $70 \%$ of which are of White ethnicity (Office for National Statistics, 2002). Prior to the Hong Kong data collection, the questionnaires were translated using guidelines suggested by van Widenfelt, Treffers, de Beurs, Siebelink, and Koudijs (2005). In brief, the items were translated into traditional Chinese characters by a team of translators who reached a common consensus. This process was followed by translation back to English by a second, independent translation team. Minor discrepancies were resolved during a meeting of the two translation teams.

After obtaining verbal permission from the principals of participating schools, informed written consent was obtained from the teachers acting in loco parentis and the students who participated in the study. Following an explanation of the study at the beginning of a timetabled PE class, the students were asked to anonymously and individually complete a multi-section questionnaire. The researcher responsible for data collection asked students to answer honestly and emphasized that there was no right or wrong answers. Data collection lasted approximately 25 minutes. 
The initial participants were 828 PE students (433 from the UK and 395 from Hong Kong, China), however, students who were born outside the country or were raised by parents or guardians born in another country may be influenced by different cultural norms than those normally associated with the resident country (McCrae, Yik, Trapnell, Bond, \& Paulhus, 1998). As a result, 113 UK students were excluded from the study. No Chinese students were excluded, giving a final sample of 715 PE students (320 from the UK and 395 from Hong Kong; 280 boys, 404 girls, and 31 unspecified; age: $M=14.41$, $S D=0.79$, range =13-15 years) from 44 classes.

\section{Measures}

Autonomy Support. Four items from the autonomy support subscale of the Teacher as Social Context questionnaire (TASC; Belmont, Skinner, Wellborn, \& Connell, 1992) were used in the present study. The items were adapted to reflect the PE context and answered using a 7-point scale, anchored by 1 (not at all true) and 7 (very true). In order to reduce participant burden we did not use all 17 items contained within the original TASC questionnaire. Instead, we chose items to reflect the four facets of autonomy support outlined by Belmont and colleagues, namely, provision of choice ("The teacher gives us a lot of choices about how we do the tasks in PE”), absence of control ("It seems like the teacher is always telling us what to do"; reverse scored), showing students respect (“The teacher listens to our ideas"), and emphasizing the relevance of tasks ("The teacher talks about how we can use things we learn in PE”). Taylor and Ntoumanis (2007) reported acceptable internal consistency and predictive validity of a longer version of the subscale in a sample of UK PE students.

Psychological Need Satisfaction. Fifteen items were used in the present study to measure PE students' contextual psychological need satisfaction. Perceptions of autonomy were measured using five items employed by Standage, Duda, and Ntoumanis (2003). 
Perceptions of competence were measured using the five item perceived competence subscale from the Intrinsic Motivation Inventory (IMI; McAuley, Duncan, \& Tammen, 1989). Perceptions of relatedness were measured using the five items from the acceptance subscale of the Need for Relatedness Scale (Richer \& Vallerand, 1998). These latter two subscales were adapted to reflect the PE context, rather than a specific activity. The items were answered using a 7-point scale, anchored by 1 (not at all true) and 7 (very true). Example items were "I feel that I do this PE class because I want to” (autonomy), "I think I am pretty good at this PE class” (competence), and “In this PE class I feel supported” (relatedness). These items have demonstrated acceptable internal consistency, in addition to adequate factorial and predictive validity, in previous UK PE-based studies (e.g., Standage et al., 2003).

Subjective Vitality. The original seven item version of the Subjective Vitality Scale (Ryan \& Frederick, 1997) was used to measure students' subjective vitality. We adapted the introductory stem to ensure that participants considered the PE context, rather than life in general. The items were answered using a 7-point scale, anchored by 1 (not at all true) and 7 (very true). An example item is "I feel alive and vital in this PE class". Ryan and Frederick reported acceptable internal consistency and factorial structure of the scale in US-based research.

Effort. Three items from the effort subscale of the IMI, adapted to the PE context, were used to measure PE students' effort in PE. An example item is “I put a lot of effort into this PE class”. The items were answered using a 7-point scale, anchored by 1 (not at all true) and 7 (very true). McAuley et al. (1989) provided evidence for the factorial structure of a four item subscale reflecting effort-importance in US-based research. We did not include the fourth item ("It was important for me to do well in this PE class"), as it aims to measure 
importance rather than effort per se. Ullrich-French and Cox (2009) reported acceptable internal consistency for scores derived from the three items used in the present study. Data Analyses

We employed multilevel modeling using MLwiN software (version 2.10; Rashbash, Steele, Browne, \& Goldstein, 2009) to explore the study hypotheses. Responses from students in the same class are more likely to be similar, compared to students from different classes (e.g., because they are influenced by the same PE teacher). This intraclass homogeneity violates the assumption of traditional least squares regression analyses that the data for each individual are independent. Multilevel analysis accounts for this dependence by modeling related equations at each hierarchical level of analysis (the student- and class-level in the present study), resulting in a more accurate estimation of the standard errors of regression coefficients and, therefore, a more precise inference of statistical significance (Hox, 2002).

Before testing the main study hypotheses, intercept-only models (i.e., no predictor variables included in the model) were constructed for all study variables to examine the variance associated with class membership. To control for possible confounding effects, age, gender and culture were entered into all subsequent multilevel regression models. Gender and culture were entered as dummy variables (Gender: $0=$ females, $1=$ males; Culture: $0=$ Hong Kong, 1 = UK). Each predictor variable was centered around the unique mean of each class (i.e., group-mean centered) and entered into the student-level equation, hence, student responses were interpreted relative to their classmates. Also, a class-aggregate of each predictor variable was entered into the class-level equation. This strategy produces uncorrelated, “pure” estimates of student- and class-level effects (Enders \& Tofighi, 2001). First, we tested whether autonomy support positively predicted subjective vitality in a multilevel model. Next, to test whether this relationship was mediated by students’ 
perceptions of autonomy, competence, and relatedness we followed the multilevel analysis procedures outlined by Krull and MacKinnon (2001). In the first step, three separate multilevel regression equations were constructed with autonomy support (the independent variable) predicting perceptions of autonomy, competence, and relatedness (the mediator variables), respectively. The second step involved a single multilevel regression equation with autonomy support and the three psychological needs predicting subjective vitality (the dependent variable). Using the regression coefficients and standard errors resulting from these equations, the statistical significance of the mediated effects were calculated using the Sobel test (Sobel, 1982) as applied to multilevel modeling by Krull and MacKinnon. These authors suggest that this method is used in multiple mediator models, such as the one tested here, because it allows for the effects of each mediator to be tested, rather than overall mediated effects.

The amount of variance in the dependent variable explained by the full model (i.e., the second step) compared to the intercept-only model was inspected using the $R_{1}{ }^{2}$ (explained student-level variance) and $R_{2}{ }^{2}$ (explained class-level variance) values. These values are an estimate of effect size, analogous to the $R^{2}$ value in single-level ordinary least squares regression analyses (Hox, 2002). This analytical process was then repeated with effort as the dependent variable. The first step in testing for mediation was identical to the analysis with subjective vitality as the outcome variable (i.e., autonomy support predicting the psychological needs).

To examine whether the student-level relationships among autonomy support and the psychological needs differed according to culture, three multilevel regression equations with each psychological need as the dependent variable were constructed. These models included the control variables (age, gender, and culture), autonomy support, and an autonomy support $\times$ culture interaction term entered as predictor variables. Two similar regression equations 
with subjective vitality and effort entered as the dependent variables, respectively, were constructed to explore cultural differences in the relationships among autonomy support and the two outcome variables. Finally, to explore cultural differences in the relationships among the psychological needs and subjective vitality/effort, two regression equations were constructed with subjective vitality and effort as the dependent variables, respectively. These two models included the control variables, the three psychological needs, and three psychological need $\times$ culture interaction terms as predictor variables. In all multilevel models examining interactions, the focal predictor was group-mean centered to obtain an accurate estimation of the cross-level interaction effects (Enders \& Tofighi, 2001). If the interaction terms in the above models were statistically significant then it was concluded that the relationship between the variables of interest differed according to culture. To interpret any significant interaction terms, we used the Johnson-Neyman technique applied to multilevel modeling (Curran, Bauer, \& Willoughby, 2006).

\section{Results}

Descriptive Statistics, Cronbach's Alpha Coefficients, and Intraclass Coefficients (ICC’s)

As shown in Table 1, the students reported levels of autonomy support, perceptions of autonomy and relatedness below the midpoint of the scale. Levels of subjective vitality, effort, and perceptions of competence were above the midpoint of the scale. Although, we analyzed the Hong Kong and UK students as one combined sample, Table 1 also provides the means and standard deviations of all variables for the two sub-samples. These are provided for information only. Cronbach’s alpha coefficients showed that all variables had acceptable internal consistency (i.e., $\alpha \geq .70$ ). The ICC's indicated that between 9 and $26 \%$ of the variance in the study variables was attributable to class membership. The Autonomy Support $\rightarrow$ Psychological Needs $\rightarrow$ Subjective Vitality Relationships 
Results of the multilevel models testing whether the relationship between autonomy support and subjective vitality was mediated by perceptions of autonomy, competence, and relatedness can be seen in Table 2 . We also report the regression coefficients and standard errors of the control variables, however, these parameters are provided for information only as they are not directly related to our study hypotheses. At both the student- and class-levels, autonomy support positively predicted subjective vitality. In the first step of Krull and MacKinnon’s (2001) guidelines for testing mediation, autonomy support positively predicted perceptions of autonomy, competence, and relatedness at both the student- and class-levels. At the student-level, step 2 revealed that all three psychological needs, but not autonomy support, positively predicted subjective vitality, indicating mediation effects. Examination of the Sobel $z$ score for each mediation pathway confirmed that all three psychological needs mediated the relationship between autonomy support and subjective vitality (Autonomy: $z=3.55, p<.001$; Competence: $z=8.14, p<.001$; Relatedness: $z=$ 8.53, $p<.001)$. At the class-level, only perceptions of competence positively predicted subjective vitality, ruling out mediation effects of perceptions of autonomy and relatedness. Examination of the Sobel $z$ score confirmed that class levels of competence significantly mediated the relationship between class levels of autonomy support and subjective vitality ( $\mathrm{z}$ $=2.34, p<.05)$. The $\mathrm{R}_{1}{ }^{2}$ and $\mathrm{R}_{2}{ }^{2}$ statistics indicated that the inclusion of predictor variables in the full mediation model explained $74 \%$ of the variance in subjective vitality at the student-level and $74 \%$ of the variance at the class-level.

\section{The Autonomy Support $\rightarrow$ Psychological Needs $\rightarrow$ Effort Relationships}

Results of the multilevel models testing whether the relationship between autonomy support and effort was mediated by perceptions of autonomy, competence, and relatedness can be seen in Table 2. Again, we provide the regression coefficients and standard errors of the control variables for information only. At both the student- and class-levels, autonomy 
support positively predicted effort. In the first step of the mediation analysis, autonomy support positively predicted perceptions of autonomy, competence, and relatedness at both the student- and class-levels (this step is identical to the analysis with subjective vitality as the outcome variable, because the outcome variable is not included in these models). At the student-level, step 2 revealed that perceptions of competence and relatedness, but not perceptions of autonomy nor autonomy support, positively predicted effort. Examination of the Sobel $z$ scores confirmed that perceptions of competence and relatedness mediated the relationship between autonomy support and effort (Competence: $z=7.97, p<.001$; Relatedness: $z=3.05, p<.01)$. At the class-level, only perceptions of competence positively predicted subjective vitality, ruling out mediation effects of perceptions of autonomy and relatedness. Examination of the Sobel $z$ score confirmed that class levels of competence significantly mediated the relationship between class levels of autonomy support and effort $(\mathrm{z}=2.34, p<.05)$. The $\mathrm{R}_{1}{ }^{2}$ and $\mathrm{R}_{2}{ }^{2}$ statistics indicated that the inclusion of predictor variables in the full mediation model explained $61 \%$ of the variance in effort at the studentlevel and $88 \%$ of the variance at the class-level.

Cultural Differences in the Autonomy Support $\rightarrow$ Psychological Needs $\rightarrow$ Subjective Vitality/Effort Relationships

Results of the multilevel models testing the cultural differences in the student-level relationships among autonomy support, psychological need satisfaction, subjective vitality and effort are shown in Table 3. The regression coefficients and standard errors of the main effects are reported for information only, as they do not relate to the study hypotheses. Results revealed that the relationship between autonomy support and perceptions of competence differed across culture. Post-hoc analyses found that the simple slopes for both the UK and Hong Kong samples were significant $(b=.28, z=5.04, p<.001$, and $b=.47, z=$ 8.38, $p<.001$, respectively), but the relationship between autonomy support and perceptions 
of competence was stronger in the Hong Kong sample. Also, the relationship between perceptions of relatedness and effort was also found to differ across cultures. Post-hoc analyses found that the simple slope for the UK sample was significant $(b=.21, z=4.31, p<$ $.001)$, but the simple slope for the Chinese sample was non-significant $(b=.03, z=0.47, p=$ ns). All other relationships were similar across cultures.

\section{Discussion}

The purpose of the present study was to examine whether Hong Kong Chinese and UK PE students’ perceptions of teacher autonomy support positively predicted their subjective vitality and effort in PE via the satisfaction of three psychological needs for autonomy, competence, and relatedness. In addition, we explored cultural differences in the relationships among the variables of interest. Previous research has paid little attention to a) the direct relationships among PE students' psychological needs and desirable consequences, b) cultural variation in the relationships among autonomy support, psychological need satisfaction, subjective vitality and effort, and c) student- and class-level effects within these relationships. The results of the study generally supported the pan-cultural theoretical tenets of BPNT (Ryan \& Deci, 2000).

Individual students’ perceptions of autonomy support relative to their class mates were positively related to their subjective vitality and effort in PE, and these relationships were mediated by students’ psychological need satisfaction. Specifically, the autonomy support $\rightarrow$ subjective vitality relationship was mediated by all three psychological needs, with relatively stronger effects through perceptions of competence and relatedness, compared to perceptions of autonomy. Moreover, the autonomy support $\rightarrow$ effort relationship was mediated by perceptions of competence and to some degree perceptions of relatedness. In addition to these student-level relationships, class average perceptions of autonomy support 
were positively associated with students’ effort and subjective vitality. Both these relationships were mediated by class average perceptions of competence.

Our finding that individual perceptions of autonomy support were positively related to all three psychological needs is in line with previous research (e.g., Standage et al., 2003). Taylor and Ntoumanis (2007) found a non-significant relationship between autonomy support and students' perceptions of competence, however, these authors included simultaneous contextual variables (i.e., students' perceptions of a structured and emotionally involved environment) in their analysis. Nonetheless, our results offer an important extension by implying that two students from different classes who perceive that they receive the same amount of autonomy support will differ in their reported psychological need satisfaction as a function of their class mates' perceptions. For example, a student who participates in a PE class where all the students perceive that they are offered choices and given responsibility will report lower psychological need satisfaction, compared with another student who takes part in a PE class where his peers perceive that the teacher does not support their autonomy. This suggests that a PE student's unique frame of reference is an important feature of the PE context to consider when exploring the link between autonomy support and psychological need satisfaction.

Our results also suggest that classes with higher average perceptions of autonomy support are more likely to contain students with higher perceptions of competence, but not higher perceptions of autonomy and relatedness. This implies that class-level interventions aimed at increasing autonomy support (e.g., training teachers' to be more generally autonomy supportive) may only positively impact upon students’ perceptions of competence, whereas, student-specific interventions based around autonomy support (e.g., increasing student awareness of opportunities for autonomy) may be necessary to positively influence all three psychological needs. 
Contrary to our exploratory hypothesis, the relationship between autonomy support and perceptions of competence was stronger in the Hong Kong Chinese students, than in the UK students. In accordance with our hypothesis, however, the relationships among autonomy support, perceptions of autonomy and relatedness were similar across cultures. Supporting autonomy in collectivist cultures is viewed by some scholars as unimportant, and even detrimental, to one's well-being (e.g., Schwartz, 1994). Contrastingly, the degree to which the environment is autonomy supportive versus controlling has been shown to be positively related to psychological need satisfaction and autonomous forms of motivation in other collectivist and authoritarian cultures, such as South Korea and Russia (Chirkov \& Ryan, 2001; Jang et al., 2009), as well as individualist cultures (Taylor \& Ntoumanis, 2007). Our results support this latter argument and imply that autonomy supportive teacher behaviors may be an important need satisfying strategy in both cultures, but especially central in enhancing Chinese PE students’ perceptions of competence. This particularly important influence of teachers' autonomy support in the Chinese classes may be explained by the fact that Chinese culture is entwined with Confucian ideologies such as filial piety (i.e., showing respect for elders). As a result of these principles, behaviors by the respected elder - the teacher - may be more influential in Chinese classes than in UK education contexts.

Referring to the next step in the hypothesized mediation process, our results revealed that students with higher perceptions of all three psychological needs relative to their class peers reported higher subjective vitality. Moreover, individual perceptions of competence and relatedness relative to their class mates significantly and positively predicted effort in PE. It is well established that promoting students' competence is of central importance in PE classes (e.g., Ntoumanis, 2001), whereas the positive effects of supporting students' needs for autonomy and relatedness are less recognized. Our findings imply that the PE environment 
should focus on supporting all three psychological needs to promote students' contextual well-being and effort, rather than the conventional focus on skill enhancement.

The non-significant relationship between perceptions of autonomy and students’ effort was somewhat unexpected; however, Ntoumanis (2001) also found competence and relatedness, but not perceptions of autonomy, to be indirectly related to effort in PE. Furthermore, Sheldon and Elliot (1998; Study 2) found that autonomous and non-autonomous goal striving predicted initial intended effort towards personal goals, whereas only autonomous goal striving predicted sustained effort. Hence, in the present study it is plausible that the positive long-term effects of autonomy were not revealed through the cross-sectional data and only the mixed short-term effects of high and low autonomy were observed, resulting in a non-significant relationship between autonomy and effort. It is also worth commenting that four of the five items used to evaluate autonomy in the present study measured the amount of choice the student perceived he/she has in PE lessons. Houlfort, Koestner, Joussemet, Nantel-Vivier, and Lakes (2002) distinguished between this decisional element of autonomy, and affective autonomy which refers to the degree of pressure one feels to complete activities. Also, Reeve, Nix, and Hamm (2003) decomposed autonomy into choice, volition, and internal perceived locus of causality and found that, compared with choice, the latter two elements were stronger predictors of students' intrinsic motivation. Future investigators may wish to explore the relationships among different aspects of autonomy and important student outcomes. Such research may provide insight into the somewhat equivocal associations among autonomy in PE and adaptive student outcomes.

The student-level relationships described above again imply that students’ contextual frame of reference is important in determining the impact of satisfying students’ psychological needs on their well-being and effort in PE. For instance, two students may report the same degree of perceived psychological need satisfaction, yet, one student feels 
more vital and puts forth more effort because her class consists of students with lower psychological need satisfaction, compared with another student whose class is full of highly autonomous, competent, and valued students. This suggests that integrating social comparison paradigms (e.g., Suls \& Wheeler, 2000) with motivational theories, such as BPNT, may extend our knowledge on the effects of satisfying individuals’ psychological needs.

At the class-level, only perceptions of competence were positively associated with students’ subjective vitality and effort. This is the first study to examine such class-level effects and infers that class-level interventions aimed at promoting students well-being and effort in PE should focus on competence enhancing strategies. On the other hand, it may not be so beneficial to target class levels of autonomy and relatedness, as these variables were unrelated to students’ vitality and effort. Instead, it may be more fruitful to target individual students’ perceptions of these two psychological needs.

The examination of cultural differences in the relationships among psychological need satisfaction and the two outcome variables unearthed little variation across Chinese and UK students. The solitary difference observed was the relationship between perceptions of relatedness and effort was non-significant in the Hong Kong student sample, but significant in the UK sample. This finding suggests that Hong Kong students do not necessarily require feelings of connectedness to their PE teacher in order to put forth effort in PE. Apart from this solitary cultural difference, the relationship among the psychological needs and outcomes were similar across the two cultures. Importantly, autonomy was a significant predictor of subjective vitality irrespective of culture. This finding is in accordance with previous crosscultural research findings and supports the universal nature of autonomy need satisfaction in facilitating optimal well-being (Chirkov \& Ryan, 2001; Chirkov et al., 2003; Deci et al., 
2001; Ryan \& Deci, 2000). Overall, these cross-cultural similarities imply that, regardless of culture, BPNT is a justifiable framework to explore PE students' experiences.

\section{Future Directions and Limitations}

In the present study we extended the extant literature by adopting a BPNT approach to the study of relationships among PE students' psychological needs, subjective vitality and effort in individualist and collectivist cultures. This research also reveals several potential future research avenues. For instance, in our study we excluded all non-native children or those that lived with immigrants. While this criterion did not impact the Hong Kong sample, it resulted in a considerable exclusion of UK PE students. By focusing on students native to the UK, our results were not blurred by possible extraneous variables. However, international sojourners have been found to experience well-being and vitality when their psychological needs are supported (e.g., Vansteenkiste, Lens, Soenens, \& Luyckx, 2006), suggesting that some of our findings may replicate with non-native student participants. In the future researchers may wish to explore this possibility. In addition, researchers may wish to consider examining the cultural orientations of the specific sample used in the study, rather than relying on assumed differences in cultural orientations based on previous, albeit convincing, research (e.g., Chinese Culture Connection, 1987; Hofstede, 2001)

Second, we examined only one potential source of psychological need satisfaction, that of teacher autonomy support. Future research may wish to cross-culturally examine alternative sources of need satisfaction such as the provision of structure or an emotionally involved environment (Taylor \& Ntoumanis, 2007). It is possible that the effects of these teacher motivational strategies may vary as a function of the cultural context. Moreover, alternative outcomes of psychological need satisfaction may also be cross-culturally explored. From a public health perspective, for example, it may be fruitful to investigate if 
the relationships between need satisfying experiences and leisure-time physical activity differ according to culture.

Third, future research may wish to build upon the cross-sectional relationships identified in the present study. For instance, longitudinal research examining adolescents over several years may shed insight into the reasons why youth, in particular girls, decline in levels of PE participation over this important time period (Ntoumanis, Barkoukis, \& Thøgersen-Ntoumani, 2009). Additionally, longitudinal studies can investigate whether the relationships among the psychological needs, subjective vitality, and effort change developmentally. Experimental manipulation of PE students' psychological needs is also warranted to establish the direction of the relationships among psychological needs and motivational outcomes. For example, in the present study we inferred that enhancing students' sense of competence will lead to greater effort in PE, however, it is plausible that the reverse relationship is also true. These methodological extensions may be preceded by the development and validation of PE-specific measures that tap students’ psychological need satisfaction, as opposed to relying on existing measures from alternative contexts. This validation should include testing for the statistical invariance of these new measures across different countries (e.g., through the use of differential item functioning; Zumbo, 2007), so that the cross-cultural investigation of the three psychological needs can prosper.

\section{Conclusion}

In this study we examined the degree to which PE students' perceptions of autonomy support predicted their effort and subjective vitality via satisfaction of the psychological needs associated with SDT. Significant relationships among the variables of interest across UK and Hong Kong Chinese samples provided empirical support for BPNT in PE settings and supported the cross-cultural relevance of SDT. Additionally, evidence was found that 
students' contextual frame of reference should be considered when exploring the relationships between autonomy support, psychological needs, vitality, and effort. 


\section{References}

Baard, P. P., Deci, E. L., \& Ryan, R. M. (2004). Intrinsic need satisfaction: A motivational basis of performance and well-being in two work settings. Journal of Applied Social Psychology, 34, 2045-2068.

Baumeister, R. F., \& Leary, M. R. (1995). The need to belong: Desire for interpersonal attachments as a fundamental human motivation. Psychological Bulletin, 117, 497529.

Belmont, M., Skinner, E., Wellborn, J., \& Connell, J. (1992). Teacher as social context: A measure of student perceptions of teacher provision of involvement, structure and autonomy support. Rochester, NY: University of Rochester.

Census \& Statistics Department (2010, March 18). Population and vital events. Retrieved from http://www.censtatd.gov.hk/hong_kong_statistics/statistics_by_subject/index. jsp?subjectID=1\&charsetID=1\&displayMode=T.

Chao, R. K., \& Tseng, V. (2002). Asian and American parenting. In M. Bornstein (Ed.), Handbook of parenting (pp. 59-94). Mahwah, NJ: Erlbaum.

Chinese Culture Connection (1987). Chinese values and the search for culture-free dimensions of culture. Journal of Cross Cultural Psychology, 18, 143-164.

Chirkov, V. I. (2009). A cross-cultural analysis of autonomy in education: A selfdetermination theory perspective. Theory and Research in Education, 7, 253-262.

Chirkov, V. I., \& Ryan, R. M. (2001). Parent and teacher autonomy support in Russian and U.S. adolescents: Common effects on well-being and academic motivation. Journal of Cross Cultural Psychology, 32, 618-635.

Chirkov, V. I., Ryan, R. M., Kim, Y., \& Kaplan, U. (2003). Differentiating autonomy from individualism and independence: A self-determination theory perspective on 
internalization of cultural orientations and well-being. Journal of Personality and Social Psychology, 84, 97-110.

Curran, P. J., Bauer, D. J., \& Willoughby, M. T. (2006). Testing and probing interactions in hierarchical linear growth models. In C. S. Bergeman \& S. M. Boker (Eds.), The Notre Dame Series on Quantitative Methodology: Vol. 1. Methodological issues in aging research (pp. 99-129). Mahwah, NJ: Erlbaum.

Deci, E. L., \& Ryan, R. M. (2000). The 'what' and 'why' of goal pursuits: Human needs and the self-determination of behavior. Psychological Inquiry, 11, 227-268.

Deci, E. L., Ryan, R. M., Gagné, M., Leone, D. R., Usunov, J., \& Kornazheva, B. P. (2001). Need satisfaction, motivation, and well-being in the work organizations of a former eastern bloc country. Personality and Social Psychology Bulletin, 27, 930-942.

Enders, C. K. \& Tofighi, D. (2001). Centering predictor variables in cross-sectional multilevel models: A new look at an old issue. Psychological Methods, 12, 121-138.

Gagné, M., Ryan, R. M., \& Bargmann, K. (2003). Autonomy support and need satisfaction in the motivation and well-being of gymnasts. Journal of Applied Sport Psychology, 15, 372-390.

Hagger, M. S., Chatzisarantis, N. L., Barkoukis, V., Wang, C. K., \& Baranowski, J. (2005). Perceived autonomy support in physical education and leisure-time physical activity: A cross- cultural evaluation of the trans-contextual model. Journal of Educational Psychology, 97, 287-301.

Hardre, P. L., Chen, C., Huang, S., Chiang, C., Jen, F., \& Warden, L. (2006). Factors affecting high school students' academic motivation in Taiwan. Asia Pacific Journal of Education, 26, 198-207.

Heine, S. J., Lehman, D. R., Markus, H. R., \& Kitayama, S. (1999). Is there a universal need for positive self-regard? Psychological Review, 106, 766-794. 
Hofstede, G. (2001). Cultures consequences: Comparing values, behaviors, institutions, and organizations across nations ( $2^{\text {nd }}$ Ed.). Thousand Oaks, CA: Sage.

Hox, J. (2002). Multilevel analysis: Techniques and applications. London, UK: Erlbaum.

Houlfort, N., Koestner, R., Joussemet, M., Nantel-Vivier, A., \& Lekes N. (2002). The impact of performance-contingent rewards on perceived autonomy and competence. Motivation and Emotion, 26, 27-295.

Iyengar, S. S., \& Lepper, M. R. (1999). Rethinking the value of choice: A cultural perspective on intrinsic motivation. Journal of Personality and Social Psychology, 76, 349-366.

Jang, H., Reeve, J., Ryan, R. M., \& Kim, A. (2009). Can self-determination theory explain what underlies the productive, satisfying learning experiences of collectivistically oriented Korean students? Journal of Educational Psychology, 101, 644-661.

Kim, H., \& Markus, H. R. (1999). Deviance or uniqueness, harmony or conformity? A cultural analysis. Journal of Personality and Social Psychology, 77, 785-800.

Kitayama, S., Snibbe, A. C., Markus, H. R., \& Suzuki, T. (2004). Is there any “free” choice? Self and dissonance in two cultures. Psychological Science, 15, 527-533.

Krull, J. L., \& MacKinnon, D. P. (2001). Multilevel modeling of individual and group level mediated effects. Multivariate Behavioral Research, 36, 249-277.

Lonsdale, C., Hodge, K. \& Rose, E. A. (2009). Burnout in elite sport: A self-determination perspective. Journal of Sports Sciences, 27, 785-795.

Lonsdale, C., Sabiston, C. M., Raedeke, T. D., Ha, S. C. A., \& Sum, K. W. R. (2009). Selfdetermined motivation and students' physical activity in physical education classes and free-choice periods. Preventive Medicine, 48, 69-73.

Markus, H. R., \& Kitayama, S. K. (2003). Models of agency: Sociocultural diversity in the construction of action. In V. Murphy-Berman \& J. J. Berman (Eds.), Nebraska 
Symposium on Motivation: Vol. 49. Crosscultural differences in perspectives on the self (pp. 1-57). Lincoln, NE: University of Nebraska Press.

McAuley, E., Duncan, T., \& Tammen, V. V. (1989). Psychometric properties of the Intrinsic Motivation Inventory in a competitive sport setting: A confirmatory factor analysis. Research Quarterly for Exercise and Sport, 60, 48-58.

McCrae, R. R., Yik, M. S., Trapnell, P. D., Bond, M. H., \& Paulhus, D. L. (1998). Interpreting personality profiles across cultures: Bilingual, acculturation, and peer rating studies of Chinese undergraduates. Journal of Personality and Social Psychology, 74, 1041-1055.

Nagasaku, M. \& Arai, K. (2005). Autonomous motivation to enter high school and school adjustment: A short-term longitudinal study. Japanese Journal of Educational Psychology, 53, 516-528.

Ntoumanis, N. (2001). A self-determination approach to the understanding of motivation in physical education. British Journal of Educational Psychology, 71, 225-242.

Ntoumanis, N., Barkoukis, V., \& Thøgersen-Ntoumani, E. C. (2009). Developmental trajectories of motivation in physical education: course, demographic differences and antecedents. Journal of Educational Psychology, 101, 717-728.

Office for National Statistics (2002, March 18). Birmingham’s population. Retrieved from http://www.birmingham.gov.uk/cs/Satellite?c=Page\&childpagename=Planning-andRegeneration\%2FPageLayout\&cid=1223096353755\&pagename=BCC\%2FCommon \%2FWrapper\%2FWrapper.

Rashbash, J., Steele, F., Browne, W. J., \& Goldstein, H. (2009). A user's guide to MLwiN (Version 2.10). Bristol, UK: University of Bristol. 
Ratelle, C. F., Guay, F., Vallerand, R. J., Larose, S., \& Senécal, C. (2007). Autonomous, controlled, and amotivated types of academic motivation: A person-oriented analysis. Journal of Educational Psychology, 99, 734-746.

Reeve, J., Jang, H., Carrell, D., Jeon, S., \& Barch, J. (2004). Enhancing students' engagement by increasing teachers' autonomy support. Motivation and Emotion, 28, 147-169.

Reeve, J., Nix, G., \& Hamm, D. (2003). Testing models of the experience of selfdetermination in intrinsic motivation and the conundrum of choice. Journal of Educational Psychology, 95, 375-392.

Richer, S. F., \& Vallerand, R. J. (1998). Construction et validation de l'échelle du sentiment d'appartenance social (Construction and validation of the perceived relatedness scale). Revue Européenne de Psychologie Appliquée, 48, 129-137.

Roth, G., Kanat-Maymon, Y., Assor, A., \& Kaplan, H. (2006). Assessing the experience of autonomy in new cultures and contexts. Motivation and Emotion, 30, 365-376.

Ryan, R. M., \& Deci, E. L. (2000). Self-determination theory and the facilitation of intrinsic motivation, social development, and well-being. American Psychologist, 55, 68-78.

Ryan, R. M., \& Frederick, C. M. (1997). On energy, personality and health: Subjective vitality as a dynamic reflection of well-being. Journal of Personality, 65, 529-565.

Schwartz, S. H. (1994). Beyond individualism/collectivism: New cultural dimensions of values. In U. Kim, H. C. Triandis, C. Kagitcibasi, S.-C. Choi, \& G. Yoon (Eds.), Individualism and collectivism: Theory, methods, and applications (pp. 85-119). Thousand Oaks, CA: Sage.

Sheldon, K. M., \& Elliot, A. J. (1998). Not all personal goals are personal: Comparing autonomous and controlling goals on effort and attainment. Personality and Social Psychology Bulletin, 24, 546-557. 
Sheldon, K. M., Elliot, A. J., Kim, Y., \& Kasser, T. (2001). What is satisfying about satisfying events? Testing 10 candidate psychological needs. Journal of Personality and Social Psychology, 89, 325-339.

Sheldon, K. M., Elliot, A., Ryan, R. M., Chirkov, V. I., Kim, Y., Wu, C., Demir, M., \& Sun, Z. (2004). Self-concordance and subjective well-being in four cultures. Journal of Cross Cultural Psychology, 35, 209-223.

Sobel, M. E. (1982). Asymptotic confidence intervals for indirect effects in structural equation models. Sociological Methodology, 13, 290-312.

Standage, M., Duda, J. L., \& Ntoumanis, N. (2003). A model of contextual motivation in physical education: Using constructs and tenets from self-determination and goal perspective theories to predict leisure-time exercise intentions. Journal of Educational Psychology, 95, 97-110.

Suls, J. \& Wheeler, L. (Eds.). (2000). Handbook of social comparison: Theory and research. New York: Plenum.

Taylor, I. M., \& Ntoumanis, N. (2007). Teacher motivational strategies and student selfdetermination in physical education. Journal of Educational Psychology, 99, 747-760.

Taylor, I. M., \& Ntoumanis, N., Standage, M., \& Spray, C. M. (in press). Motivational predictors of physical educational students’ effort, exercise intentions, and leisuretime physical activity: A multilevel linear growth analysis. Journal of Sport \& Exercise Psychology.

Trautwein, U., Lüdtke, O., Nagy, G., \& Marsh, H. W. (2009). Within-school social comparison: How students perceive the standing of their class predicts academic selfconcept. Journal of Educational Psychology, 101, 853-866. 
Ullrich-French, S., \& Cox, A. (2009). Using cluster analysis to examine the combinations of motivation regulations of physical education students. Journal of Sport and Exercise Psychology, 31, 358-379.

Vansteenkiste, M., Lens, W., Soenens, B., \& Luyckx, K. (2006). Autonomy and relatedness among Chinese sojourners and applicants: Conflictual or independent predictors of well-being and adjustment?. Motivation and Emotion, 30, 273-282.

Vansteenkiste, M., Zhou, M., Lens, W., \& Soenens, B. (2005). Experiences of autonomy and control among Chinese learners: Vitalizing or immobilizing? Journal of Educational Psychology, 97, 468-483.

van Widenfelt, B. M., Treffers, P. D. A., de Beurs, E., Siebelink, B. M., \& Koudijs, E. (2005). Translation and cross-cultural adaptation of assessment instruments used in psychological research with children and families. Clinical Child and Family Psychology Review, 8, 135-147.

White, R. W. (1959). Motivation reconsidered: The concept of competence. Psychological Review, 66, 297-333.

Wilson, P. M., Longley, K., Muon, S., Rodgers, W. M., \& Murray, T. C. (2006). Examining the contributions of perceived psychological need satisfaction to well-being in exercise. Journal of Applied Biobehavioral Research, 11, 243-264.

Zumbo, B. D. (2007). Three generations of differential item functioning (DIF) analyses: Considering where it has been, where it is now, and where it is going. Language Assessment Quarterly, 4, 223-233. 
Table 1

Means, Standard Deviations, Cronbach's Alpha Coefficients, and Intraclass Coefficients of all Study Variables

\begin{tabular}{|c|c|c|c|c|c|}
\hline \multirow[b]{2}{*}{ Variable } & \multicolumn{3}{|c|}{ Combined Sample } & \multirow{2}{*}{$\begin{array}{c}\text { Chinese Hong } \\
\text { Kong Sample } \\
M(S D)\end{array}$} & \multirow{2}{*}{$\begin{array}{c}\text { UK Sample } \\
M(S D)\end{array}$} \\
\hline & $M(S D)$ & $\alpha$ & $\begin{array}{c}\text { Intraclass } \\
\text { Coefficient }\end{array}$ & & \\
\hline Autonomy Support & $3.80(1.20)$ & .70 & .17 & $3.88(1.08)$ & $3.70(1.32)$ \\
\hline Autonomy & $3.32(1.33)$ & .83 & .26 & $3.73(1.23)$ & $2.81(1.28)$ \\
\hline Competence & $4.22(1.25)$ & .83 & .15 & 3.99 (1.13) & 4.49 (1.34) \\
\hline Relatedness & $3.94(1.23)$ & .84 & .09 & $3.80(1.10)$ & $4.10(1.36)$ \\
\hline Subjective Vitality & $4.07(1.29)$ & .88 & .11 & $4.12(1.20)$ & $4.01(1.39)$ \\
\hline Effort & $4.64(1.40)$ & .80 & .16 & $4.36(1.25)$ & $4.98(1.49)$ \\
\hline
\end{tabular}

Note: 7-point scales were used for all variables. 
Table 2

Regression Coefficients and Standard Errors of the Hypothesized Autonomy Support $\rightarrow$ Psychological Needs $\rightarrow$ Subjective Vitality/Effort

Mediated Relationships

\begin{tabular}{|c|c|c|c|c|c|c|c|}
\hline & \multicolumn{2}{|c|}{ Direct Relationships } & \multicolumn{3}{|c|}{ Mediation Step 1 (Vitality \& Effort) } & \multirow{2}{*}{$\begin{array}{l}\text { Mediation Step } 2 \text { (Vitality) } \\
\text { AS \& Needs } \rightarrow \text { Vitality }\end{array}$} & \multirow{2}{*}{$\begin{array}{l}\text { Mediation Step } 2 \text { (Effort) } \\
\text { AS \& Needs } \rightarrow \text { Effort }\end{array}$} \\
\hline & AS $\rightarrow$ & AS $\rightarrow$ Effort & AS $\rightarrow$ & AS $\rightarrow$ & AS $\rightarrow$ & & \\
\hline Independent & Vitality & & Autonomy & Competence & Relatedness & $b(S E)$ & $b(S E)$ \\
\hline Variable & & & $b(S E)$ & $b(S E)$ & $b(S E)$ & & \\
\hline Intercept & $2.94(.36)^{* * *}$ & $3.01(.38) * * *$ & $1.35(.40) * * *$ & $2.54(.36)^{* * *}$ & $1.87(.28)^{* * *}$ & $1.88(.35)^{* * *}$ & $1.67(.33) * * *$ \\
\hline Age & $-0.21(.12)$ & $-0.08(.13)$ & $-0.18(.13)$ & $-0.02(.12)$ & $-0.04(.10)$ & $-0.07(.09)$ & $-0.03(.09)$ \\
\hline Gender & $0.56(.11)^{* * *}$ & $0.65(.12)^{* * *}$ & $-0.11(.12)$ & $0.56(.11)^{* * *}$ & $0.21(.09)^{*}$ & $0.39(.09)^{* * *}$ & $0.34(.09)^{* * *}$ \\
\hline Culture & $-0.12(.10)$ & $0.60(.11)^{* * *}$ & $-0.71(.12)^{* * *}$ & $0.52(.10) * * *$ & $0.37(.08)^{* * *}$ & $-0.29(.13)^{*}$ & $0.28(.13)^{*}$ \\
\hline \multicolumn{8}{|c|}{ Student-level effects } \\
\hline AS & $0.50(.04)^{* * *}$ & $0.40(.04)^{* * *}$ & $0.54(.04)^{* * *}$ & $0.36(.04)^{* * *}$ & $0.59(.04)^{* * *}$ & $0.04(.03)$ & $0.04(.04)$ \\
\hline Autonomy & & & & & & $0.11(.03)^{* * *}$ & $0.03(.04)$ \\
\hline Competence & & & & & & $0.52(.03) * * *$ & $0.67(.04)^{* * *}$ \\
\hline Relatedness & & & & & & $0.35(.04)^{* * *}$ & $0.15(.05)^{* *}$ \\
\hline
\end{tabular}


AS

Autonomy

Competence

Relatedness

Note. $* p<.05$

AS = Autonomy Support
$-0.14(.10)$

$0.06(.11)$

0.16(.09)

$-0.03(.09)$

$0.36(.11)^{* *}$

$0.55(.11)^{* * *}$

$0.16(.14)$

$0.06(.15)$

$* * p<.01 \quad * * * p<.001$ 
Table 3

Regression Coefficients and Standard Errors of the Multilevel Models Exploring Cultural Differences in the Autonomy Support $\rightarrow$ Psychological Needs $\rightarrow$ Subjective Vitality/Effort Relationships

\begin{tabular}{|c|c|c|c|c|c|c|c|}
\hline Independent Variable & $\begin{array}{l}\text { AS } \rightarrow \text { Auto. } \\
b(S E)\end{array}$ & $\begin{array}{l}\text { AS } \rightarrow \text { Comp. } \\
b(S E)\end{array}$ & $\begin{array}{l}\text { AS } \rightarrow \text { Relate. } \\
b(S E)\end{array}$ & $\begin{array}{l}\text { AS } \rightarrow \text { Vitality } \\
b(S E)\end{array}$ & $\begin{array}{l}\text { AS } \rightarrow \text { Effort } \\
b(S E)\end{array}$ & $\begin{array}{l}\text { Needs } \rightarrow \text { Vitality } \\
b(S E)\end{array}$ & $\begin{array}{l}\text { Needs } \rightarrow \text { Effort } \\
b(S E)\end{array}$ \\
\hline Intercept & $3.73(.12)^{* * *}$ & $3.73(.09)^{* * *}$ & $3.66(.08) * * *$ & $3.86(.09)^{* * *}$ & $4.06(.09) * * *$ & $3.86(.08)^{* * *}$ & $4.07(.08)^{* * *}$ \\
\hline Age & $-0.23(.16)$ & $-0.05(.13)$ & $-0.07(.12)$ & $-0.22(.13)$ & $-0.07(.14)$ & $-0.16(.11)$ & $-0.00(.12)$ \\
\hline Culture & $-0.88(.15)^{* * *}$ & $0.45(.11)^{* * *}$ & $0.27(.10)^{*}$ & $-0.17(.11)$ & $0.53(.12)^{* * *}$ & $-0.17(.10)$ & $0.52(.10)$ \\
\hline AS & $0.60(.05)^{* * *}$ & $0.47(.06)^{* * *}$ & $0.63(.05)^{* * *}$ & $0.54(.06)^{* * *}$ & $0.42(.06)^{* * *}$ & - & - \\
\hline Autonomy & - & - & - & - & - & $0.11(.03)^{* * *}$ & $0.04(.04)$ \\
\hline Competence & - & - & - & - & - & $0.61(.05) * * *$ & $0.80(.07)^{* * *}$ \\
\hline Relatedness & - & - & - & - & - & $0.30(.05)^{* * *}$ & $0.03(.07)$ \\
\hline AS $\times$ Culture & $-0.08(.07)$ & $-0.19(.08)^{*}$ & $-0.04(.07)$ & $-0.05(.08)$ & $-0.02(.09)$ & - & - \\
\hline Auto. $\times$ Culture & - & - & - & - & - & $0.07(.04)$ & $0.07(.05)$ \\
\hline Comp. $\times$ Culture & - & - & - & - & - & $-0.11(.06)$ & $-0.16(.08)$ \\
\hline Relate. × Culture & - & - & - & - & - & $0.07(.06)$ & $0.18(.09)^{*}$ \\
\hline
\end{tabular}

Note. ${ }^{*} p<.05,{ }^{* *} p<.01,{ }^{* * *} p<.001, \mathrm{AS}=$ Autonomy Support; Auto. = Autonomy, Comp. = Competence, Relate. = Relatedness 